\title{
Special topic: Financial crisis
}

\author{
Mario Brandtner • Rita Laura D'Ecclesia
}

Published online: 17 June 2012

(C) Springer-Verlag 2012

In the last decades an increasing role has been played by quantitative analysis to provide support in the decision making process of business processes, bank performance and government strategies aimed to redesign their budget composition. Financial players have been excessively exposed to risk, which has been one of the main causes of the recent financial crisis. Some of these risks were used in order to take highly speculative strategies which led to bankruptcy of some very large banks and threatened the stability of the international financial system. The immediate response to this situation was the introduction of specific regulations aimed at forcing market participants to abide by better rules and transparency. Together with the introduction of specific measures, an extensive use of over the counter derivatives, such as credit default swaps, has occurred. The use of these financial instruments in combination with securitization in a quite deregulated environment has threatened the stability of the financial system. National governments opted for enormous financial support for certain parts of the banking sector. Eventually the financial crisis spread to the real sector and led to a global recession in most European countries. Moreover, the increasing public debt due to the Sub-Prime Crisis further antagonized the subsequent European sovereign debt crisis of 2009-2012.

Given these recent developments and their tremendous consequences for the global economy, there is an urgent need for an in-depth analysis of the various causes of the current global financial crisis to enable us to draw useful lessons for the future. This Special Topic "Financial Crisis" brings together three contributions

\footnotetext{
M. Brandtner

Chair of Finance, Banking and Risk Management,

Friedrich Schiller University of Jena, Jena, Germany

R. L. D’Ecclesia ( $₫)$

Department of Social and Economic Analysis,

Sapienza" University of Rome, Rome, Italy

e-mail: rita.decclesia@uniroma1.it
} 
that show the breadth and the interconnectedness of major issues related to the current financial crisis.

Ferrero, Izquierdo, and Torres analyze the role of corporate governance mechanisms during the financial crisis. It has been argued that these mechanisms have not served their purpose to adequately protect stakeholders during the recent turmoil. The authors address this issue by focusing on board characteristics and the level of debt as well-established corporate governance mechanisms, and analyze their impact on corporate performance and corporate risk taking. In particular, they differentiate between a period of economic growth and recession. Their findings show that independent board members as well as high debt lead to lower risk taking during a period of financial crisis, supporting the hypotheses that outside directors can be providers of timely information and that effective monitoring is carried out by creditors, respectively.

The paper by Bencivenga, D'Ecclesia, and Triulzi analyzes the relationship between oil price volatility and macroeconomic and financial variables. Oil price fluctuations affect consumers, producers and marketers, especially in terms of costs and incentives to invest in technology and trading strategies, and therefore can be seen as an important indicator for financial crises. In fact, empirical evidence shows that four of the last five global recessions were preceded by oil shocks. The authors analyze the role of macroeconomic and financial variables, such as interest rate, USD/Euro exchange rate, oil imports, open interest in oil futures, and the gold spot price in explaining the oil price volatility. They apply a Vector Error Correction Model framework in order to test the existence of a long run equilibrium in the oil price dynamic. The analysis shows that all the considered variables play a significant role to bring the oil price toward equilibrium, with the gold spot price and the USD/EUR exchange rate being weakly exogenous and therefore the key drivers.

Castellano and Scaccia study the relationship between the credit default swap (CDS) market and rating events. Rating agencies in the recent financial crisis have been considered responsible for methodological errors and unresolved conflicts of interest, leading to an underestimation of the risk associated with credit derivative products. On the other hand, credit default swaps serve as an important source of direct information on a company's creditworthiness by providing the market price of credit risk. Therefore, it is natural to ask whether the CDS market anticipates rating events or, conversely, whether the CDS market predicts rating events. The present paper addresses the first research question. By combining the event study methodology with Markov switching models, it becomes possible to model statedependent means and variances, and to consider effects such as heteroscedasticity and volatility clustering in the data. The analysis is employed on a pre-crisis period 2004-2006, and an actual crisis-period 2007-2009, in order to verify whether a change in the signaling power of CDS quotes can be found during the financial turmoil. The results indicate that announcements made by rating agencies do not convey extra information but reflect information already discounted by the market. Therefore, market participants do not seem to rely on rating agencies announcements; this lack of confidence is much more pronounced during the period of financial crisis. 
The papers presented here contribute to an in-depth analysis of the recent financial crisis. However, as we are still being faced by several aftershocks such as the European sovereign debt crisis, a conclusive long term reflection is impossible at present. Nonetheless, the results presented in this Special Topic can lead the way to ongoing research in this field, and support the academic and political debate on effective policy solutions to avoid, or at least mitigate, future crises. 